\title{
Being an Instructional Designer: a Job requiring Innovation and Trust Être conseiller ou conseillère pédagogique, un travail d'innovation et de confiance
}

\section{Serge Gerin-Lajoie}

\begin{abstract}
This case study deals with the development and implementation of two online art courses. It outlines the concerns of the faculty member responsible for these courses and those of the instructional designer assisting him. The key design issues deal with the management of copyright material available via the Internet, the difficulty of implementing innovative educational strategies, and the use of new Web 2.0 tools. This case study highlights the challenges of the relationship between an instructional designer and a professor in the context of instructional and technological innovation.
\end{abstract}

Key words: Canada - arts - redesign - instructional strategies - tools - Web 2.0 instructional designer

\section{The institutional context}

This case is set in a medium-sized, dual mode Canadian university - King's University (KU) - that offers more than 500 courses and approximately 50 programs completely online. The online courses represent just over $10 \%$ of the total number of courses offered by the university.

There is no compulsory model of instructional design used at KU. The Office of Teaching and Learning (OTL) suggests using an adaptation of the Gagné and Briggs 
(1979) model but this remains a recommendation and not a standard procedure of development. The face-to-face teaching culture and the best practices in distance education (DE) developed over the last 25 years by faculty members and instructional designers, specializing in $\mathrm{DE}$, are the main models influencing the development of distance education courses at $\mathrm{KU}$.

In this case, the instructional approach recommended by the faculty member did not lend itself very well to established $\mathrm{DE}$ practices or even to a more general model of instructional design. The time had also come to introduce new and innovative educational tools that surpassed or replaced the practices that had, over time, become institutional best practices.

\section{The participants}

Marc: Instructional designer specializing in $\mathrm{DE}$. $\mathrm{He}$ has been a member of the instructional design team in the OTL for the last few years and has assisted in the development of online learning projects in the Faculty of Fine Arts. During a 2-year period, he assisted Robert in the development of his two face-to-face and online courses.

Patrick: Adjunct Professor in the Faculty of Fine Arts, a specialist in the history of art. He has worked on the development of a new digital arts program and has been expecting to receive a grant for a research and innovation digital arts laboratory. He is in charge of several history of art courses. Over the past year, he developed his first online course in association with Marc.

Robert: Associate Professor, a specialist in the anthropology of art. He holds a doctoral degree and is renowned for his expertise in the field. Robert has a lot of field experience, 
travelling regularly to collect data and artistic artifacts in various communities around the world. He is contracted on a regular basis by production companies and museums to develop exhibits. In addition to his numerous expeditions, he teaches in various Canadian and international universities. He has developed good skills in Information and Communication Technologies (ICT) but has never studied or taught via DE.

\section{The specific features of the case}

Marc was given the mandate to develop two online courses, called "C1" and "C2" in this text, in the field of folk art. The project was initiated by Patrick, the professor in charge of these courses, and the Dean of the Faculty of Fine Arts. Over the last few years, these face-to-face courses were typically taught every two or three years, depending on Patrick's availability. However, given his current need to set up his new research laboratory, it is expected that Patrick will no longer be able to teach these courses. Moreover, the number of students enrolled in these courses has been relatively low given scheduling conflicts with other Fine Arts courses and the infrequency with which these courses have been offered in the past.

According to Patrick, the main reasons for putting these courses online include:

For the Faculty of Fine Arts, it would ensure the ongoing availability of these courses and allow for more flexibility in student scheduling. Furthermore, an online version of these courses could even attract a new category of students for $K U$, because their content could be of interest to people outside the Faculty of Fine Arts. It is not necessary for students to have preliminary knowledge in the field of the folk arts to enroll in these courses.

These courses are part of several three-year bachelor's degree programs (Art, History of Art and Art Education) as well as a certification program (Artistic Culture), all programs offered by the Faculty of Fine Arts. 
In spite of the fact that the Faculty of Fine Arts had very little experience in DE, Patrick managed to convince faculty management to hire Robert as an associate professor, to teach both face-to-face courses during two consecutive terms, and then to put both of them online for the following year. Once this was done, Robert would supervise the students enrolled in these new online courses.

As indicated in Table 1, the case timeline extended over a two-year period. During the first year, Robert was expected to offer both face-to-face (F2F) courses (C1 and C2), and to oversee the online design of the courses so that, in the second year, they could be offered online $(\mathrm{O})$.

\begin{tabular}{|c|c|c|c|c|}
\hline \multicolumn{2}{|c|}{ Table 1 - Case Timeline } \\
\hline Year & \multicolumn{2}{|c|}{1} & \multicolumn{2}{c|}{} \\
\hline Term & Fall & Winter & Fall & Winter \\
\hline \multirow{2}{*}{ Robert's } & Offer course C1-F2F & Offer course C2- & & \\
\cline { 2 - 5 } & & Design online courses C1-O and C2-O & Offer course C1-O & Offer course \\
& & & & C2-O \\
\hline
\end{tabular}

Legend: $\mathrm{C}=$ Courses, $\mathrm{F} 2 \mathrm{~F}=$ Face-to-Face, $\mathrm{O}=$ Online 


\begin{abstract}
Meta-reflection: Marc's initial worries. Marc considers this start-up project to be one of the most stressful he's ever experienced. He has been an instructional designer, specializing in DE, for less than two years and he fears that he may not have enough experience. KU wants to develop new courses and online programs but the Faculty of Fine Arts has very little experience in DE. The first course developed by Patrick and Marc was sufficient, but not noteworthy. Personally, Marc could not tell if Patrick was enthusisatic or even satisfied after the completion of the course. Moreover, at the faculty level, the success or failure of these two new online courses could have a positive or a negative impact on the development of future online courses. Therefore, Marc must ensure that everything works as it should, since, in his mind, the very credibility of distance education is at stake among faculty members in the Faculty of Fine Arts.
\end{abstract}

\title{
The project start-up
}

In spite of Patrick's best efforts, Robert's appointment as associate professor was delayed. It wasn't until August that the final strings were pulled and Robert could begin the process of developing his face-to-face courses $(\mathrm{C} 1-\mathrm{F} 2 \mathrm{~F}$ and $\mathrm{C} 2-\mathrm{F} 2 \mathrm{~F})$ for the following academic year. As soon as Robert was officially appointed, an initial meeting with Marc was scheduled.

Their first meeting provided an opportunity for Marc and Robert to get to know one another. Although Marc knew that the two courses would be offered F2F during the first year, he nevertheless took this opportunity to present his ideas about the online versions to be developed. He also explored Robert's knowledge and expertise in DE. This first 
meeting was rather cordial and they both found mutual points of interest since Marc had taken art courses in the past.

Robert: $\quad$ The content of these two courses follows a chronological plan. The first (C1) deals with folk art at the beginning of the $20^{\text {th }}$ century while the second (C2) deals with folk art from the 1970s until today.

Marc: $\quad$ OK, I see. So the two courses are linked. Got it! By the way, I was wondering if you have any prior experience in distance education or online learning?

Robert: No, but I consider myself a good ICT user, particular with the LMS that KU uses.

Marc quickly realized that Robert's main teaching concerns dealt with the development of the F2F courses, the first of which was scheduled for the Fall term which was just a few days away. They agreed to wait until after the start of the first F2F courses before thinking about the online versions.

\section{Meta-reflection: The ideal game plan for Marc}

For Marc, it was preferable to develop the F2F courses using a similar design approach as the one he would use to develop the online versions. This would allow the development of reusable learning materials as well as the use of the LMS for both learning modes: face-to-face and online. However, Marc wanted to make sure that Robert shared this line of thinking and that he would not limit his F2F courses to a specific style of classroom teaching. Marc believed that he should help Robert develop his F2F courses but also wanted to challenge him to go beyond his traditional teaching methods to incorporate best practices in DE. 


\section{The rubber hits the road}

During the Fall term, while Robert taught the C1-F2F course, another meeting took place between Marc and Robert to explore Robert's intentions regarding the development of the online version of this course $(\mathrm{C} 1)$ as well as $\mathrm{C} 2$. The usual design elements were discussed: learning activities, various kinds of learning materials, evaluation methods, and so on. At first glance, the structure of the courses seemed to assume a "classic" online course style. That is, they would consist of modules in which the students would read a collection of texts and then answer questions on a weekly basis.

Robert: In my classroom courses, I use a lot of material from the Internet. I regularly present videos, audio clips and pictures in order to contextualize various aspects I want the students to learn. In the folk arts field, there aren't many volumes or reference books. Those that do exist are written in a very academic style and approach folk art from angles that I don't always agree with. Then again, other books use an historic approach to the arts. I try to demonstrate that folk art is "alive" and is in a constantly evolving state. I would define my approach as being more holistic.

Marc: $\quad$ The use of material downloaded from the Internet is relatively easy to use in a classroom, but it is not possible to integrate this material into an online course. It is necessary to respect copyright restrictions.

Robert: I I understand but I don't know what can be done about this issue. These resources are necessary for me to illustrate my points and to help my students realize that art is always set in a social context.

Marc: $\quad H a v e$ you consider simply providing links to these resources? That would allow each student to download their own materials. This is generally recommended as the best legal way to provide access to these online resources.

Robert: $\quad H o w$ can we avoid link rot and make sure that these resources will remain available online over the course of time?

Marc: $\quad$ We can't. It is very likely that some of these resources are online illegally so their availability will vary. They will change addresses or will simply disappear from the Web. It could happen during the development of the courses or, worse, while the course is being offered online.

Robert: So, we can't be certain. 
Marc: $\quad$ No.

In his face-to-face classroom courses, the use of material downloaded from the Internet was relatively easy to do. Robert could present what he wanted and he could use resources from the KU library to illustrate contents. However, for online courses, the use of this learning material could raise certain copyright protection issues. Robert was worried about this.

After a lot of discussion and consideration, a brilliant idea emerged.

Marc: Do you think it would be possible to use three to five hyperlinks for every notion, idea, or concept to be illustrated? This way, for the same notion, the probability of having all of the hyperlinks become non-functional at the same time would be quite reduced.

Robert: $\quad$ There are enough online resources available to find several links leading to images, videos, and so on to illustrate a specific notion. I am going to begin searching and selecting hyperlinks to create my modules.

In order to have Robert's students actively participate in the courses, as opposed to just getting acquainted with selected material, Marc suggested:

Marc: Why don't you ask your students to search for similar online resources and then share them via the discussion forum?

Robert: $\quad$ That's an interesting idea. We can test it in the course planned for the winter term $(C 2-F 2 F)$. What is even more interesting is that the new resources found by the students could replace the hyperlinks that will disappear during the time the course is offered.

Marc: $\quad$ That's killing two birds with one stone! You would have access to continuously updated, online resources for the courses as well as provide a means for students to become actively engaged, by having them look for resources associated with what they are learning. 


\section{Meta-reflection: An idea to avoid copyright issues}

For Marc, solving the copyright issue is a subject of concern. It is obvious that the traditional use of resources (library documents, books, collection of texts, videos) does not meet the needs of students in their distance education and online courses. In addition, the transition to the age of digital resources has not been easy at KU. The general population quickly adopted a culture of using the Internet, but the use of these resources in an instructional context is a bridge that few faculty members have crossed, except for finding hyperlinks to complement their course websites. For Marc, it is obvious that Robert counts on the availability of Internet resources and that he prioritizes their use in his teaching approach. Marc doesn't want this issue to slow Robert down in the development of his courses. Marc is happy that the strategy of using Internet resources via hyperlinks has been readily adopted by Robert. Furthermore, he is very satisfied with the idea of having Robert's students increase the hyperlinks collection.

\section{Unusual questions}

Robert was a respected expert in his field. However, the holistic learning approach that he used in his F2F courses didn't seem to work very well. According to Robert, the students were not very familiar with lecture-style presentations that dealt with concepts interconnected in complex ways (structures, styles, esthetics, etc.), included multiple perceptions, and that occurred in variable social contexts. Robert admitted that, in the classroom, students had difficulty adopting this approach: 
Robert: I realize that this approach differs from models where specialization constitutes a social and academic ideal. That is why an important part of the academic community, particularly in the arts, often operates within the boundaries of an obsolete epistemology.

A closer look at Robert's holism
The holistic approach that Robert refers to seems to comprise a way of seeing things
rather than a static theory, which is capable of explaining everything. To Marc, it is a
philosophical framework of global clarification that consists of looking into social
phenomena with all its underlying angles and factors to avoid reductionist or simplistic
interpretations. In other words, a single factor, in and by itself, cannot explain the
complexity of a phenomenon. According to Robert, the holistic method of analysis allows
for a better understanding of complex realities and artistic phenomena that occur in
society.

Robert: $\quad$ I realized that the time during which students contemplate these concepts is often limited to our three-hour weekly class. The majority of students don't readily understand or adopt the learning approach I propose due to their lack of reflection time and practice. I'm worried that these comprehension difficulties will persist and even get worse in an online course.

During these working meetings, Marc felt that Robert was starting to understand how ICTs might be employed to organize asynchronous learning activities that could be spread out over time. In other words, each activity could last longer than the time allocated in a classroom setting. 
Marc: $\quad$ What do you think of setting up discussion forums as a specific learning activity? Having your students write answers in a discussion forum would encourage them to contemplate their answers before posting them. That way, you could ask students to address open, global, and complex questions. Typically, when an activity is asynchronous, students take their time before answering, which could improve the quality of their contributions, something that is simply not possible in a face-to-face class.

Table 2 shows how the C1-O course took shape. It was organized to include 13 learning modules, with the first discussion occuring in the fourth module. This first forum would address all content presented from the beginning of the course up until the fourth module and allow for less supervision by the professor. For students, it was an activity in which they took a predetermined example of folk art and characterized the links between this kind of art and its social dimensions. The second discussion was planned for the last week of the course, in module 13. This forum was used to help students prepare for the final exam. In the forum, the students were requested to answer open, global, and complex questions to which several answers were possible, the same type of questions as those presented on the final exam.

\begin{tabular}{|c|c|c|c|c|c|c|c|c|c|c|c|c|c|}
\hline Modules & 1 & 2 & 3 & 4 & 5 & 6 & 7 & 8 & 9 & 10 & 11 & 12 & 13 \\
\hline $\begin{array}{l}\text { Forum } \\
\text { discussions } \\
\text { (FD) }\end{array}$ & & & & $\begin{array}{c}\text { FD- } \\
1\end{array}$ & & & & & & & & & $\begin{array}{c}\text { FD- } \\
2\end{array}$ \\
\hline $\begin{array}{c}\text { Questions } \\
\text { (Q) }\end{array}$ & & $\begin{array}{l}\text { Q- } \\
2\end{array}$ & $\begin{array}{l}\text { Q- } \\
3\end{array}$ & Q-4 & $\begin{array}{l}\text { Q- } \\
5\end{array}$ & $\begin{array}{l}\text { Q- } \\
6\end{array}$ & $\begin{array}{l}\text { Q- } \\
7\end{array}$ & $\begin{array}{l}\text { Q- } \\
8\end{array}$ & $\begin{array}{l}\text { Q- } \\
9\end{array}$ & $\begin{array}{l}\text { Q- } \\
10\end{array}$ & $\begin{array}{l}\text { Q- } \\
11\end{array}$ & $\begin{array}{l}\text { Q- } \\
12\end{array}$ & \\
\hline Feedback (F) & & & $\mathrm{F} 2$ & F3 & $\mathrm{F} 4$ & F5 & F6 & F7 & F8 & F9 & F10 & F11 & F12 \\
\hline
\end{tabular}


After some discussion and thought, Marc and Robert developed a question-and-answer system that applied to all of the modules. As a consequence, as indicated in Table 2, for every module where videos had been viewed and compulsory texts read, the students would have to answer open-ended questions (Q) for which there were no single right answers.

Robert: $\quad$ There will only be well thought-out and personal answers. Since the students will still be within the learning process, I think the answers should be sent to me by e-mail. It would avoid exposing their emerging thoughts to the whole group. This will allow students to develop their capacity to analyze and to criticize artistic phenomena as well as to use an applied research method. This will encourage them to develop a more holistic understanding of the artistic phenomenon.

Marc and Robert decided that, one week after the deadline, they would post answers to the questions in each module; a feedback procedure would then take place. In the first instance, Robert would give a written and annotated appreciation of each student's personal answers. Furthermore, he would supply general feedback (F) consisting of a podcast prepared from various answers received from students. This "spontaneous" feedback would highlight the students' good ideas and those that were not so useful. Moreover, Robert would use his expertise to add answers that were forgotten or underexplored by the students. These podcasts would be recorded by Robert using simple freeware allowing for the production of MP3 files, which he would then upload to the course website.

It was then decided that the answers to the questions would count for $50 \%$ of the final mark for the course. It demonstrated the importance Robert gave to the implementation of the learning approach he favoured. 


\begin{abstract}
Meta-reflection: What's bred in the bone will come out in the flesh
Marc is happy that Robert accepted his idea of providing feedback via podcasts. As soon as Marc suggested the idea, Robert accepted it right away because he was already familiar with the software used for digital recordings. Marc finds it surprising that this more natural and spontaneous form of communication, that can easily be used to produce podcasts, is not used more often at the university. While video podcasts are sometimes used to present the contents of slideshows, audio podcasts, by themselves, are seldom used to provide feedback and to supervise students. So, Marc is pleasantly surprised to find that Robert is so positive about this approach.
\end{abstract}

\title{
A change of program: towards the unknown
}

By the end of November, Marc thought that the design of Robert's courses was on the right track. After intense discussions and reflections, the main problems and issues seemed to be resolved. The learning activities, the choice of technology, the assessment methods, and the learning materials were well organized. Robert continued to teach the C1-F2F course and was actively searching for Internet resources for the second course, C2-F2F, planned for the winter term.

Marc was expecting that the design work done for the first course (C1-O) would guide the development of the second course (C2-O). It was now early December and a course team meeting took place:

Robert: $\quad$ I want to try out a new instructional approach with my students in the next online course (C2-O). I am even going to try this experiment out during the winter F2F session. I would like the students to be more involved in the 
research and construction of the course, with regards to contents. But this is still vague in my mind and I do not know exactly how I am going to do this.

As Robert's intentions are still not very clear, it is impossible for Marc to define the approach that Robert should adopt. Marc and Robert agree that it would be more efficient for Robert to take some time to finalize his idea and, upon return from the Christmas holidays-at the beginning of the Winter term-reconvene to discuss his ideas.

\section{Meta-reflection: Marc's frustration}

At this moment, Marc is actually feeling annoyed by the situation. It is disconcerting to see that all the work done on the design of Robert's first online course is about to become useless for the second course, and what makes it worse, is that Robert can not even explain what exactly he wants to do or why. Marc wonders if any of the design work done for $\mathrm{C} 1-\mathrm{O}$ will still be usable.

To be honest, Marc's frustration does not result from the fact that Robert is undecided about his new approach, but rather because he does not understand what it is that Robert wants for his C2-F2F and possibly his online version of this course. Marc cannot help and counsel him, although this is his assigned role.

Marc's appropriation of the holistic approach was already difficult to apply to Robert's first F2F course because this kind of approach is used so seldom in university teaching practice or in DE. As such, he was confronted with a style of thinking that he had never come across before in his career. The challenge of forging a new path towards the 
development of $\mathrm{C} 1-\mathrm{O}$ was considerable. To Marc, the idea of adopting another, even more ambiguous, approach was overwhelming.

Once C2- F2F had begun for the winter term, Marc sat down with Robert.

Robert: I've refined my thinking on the learning approach that I want the students to use. I've decided that I want my students to play a greater role in the search for, and consequently in the construction of, course contents. Such a postmodern stance lends itself well to this kind of collective effort. It was not the case in the fall course $(C 1-F 2 F)$ where they received the course content directly from me, which obviously required no effort from the students. However, the second course will comprise a team construction from the get-go, under my supervision. This approach is inspired by the ideas of deconstructivism among postmodern intellectuals.

In spite of Robert's richer and more thorough explanation, Marc still couldn't pinpoint exactly what Robert was trying to do.

Marc: $\quad$ Sorry, but I don't understand what you want to do. What would you say if I attended some of your F2F sessions this winter? That way, I could observe the approach you use and reflect on how to transpose it to your online course?

Robert agreed that Marc should attend some of his F2F sessions. Table 3 presents Marc's key observations. 
Table 3 - Marc's observations of Robert's C2-F2F course

Content

- Robert presented a lot of factual information.

- Robert regularly used timescales to demonstrate the evolution of various concepts.

- Robert presented many interrelated elements dealing with history, anthropology, sociology and culture to explain folk arts.

- Robert enhanced the course contents with anecdotes and personal experiences.

Learning activities

- Robert asked students a lot of questions to encourage them to contemplate and integrate factual knowledge.

- Robert provided answers to spontaneous questions and enriched his explanations with personal interpretations.

Learning material

- Robert used several excerpts from texts, images and audio or video clips from his personal material or downloaded from the Internet (YouTube, Viméo, Web sites).

The analysis of these observations led Marc to believe that there was no unique linear way to study folk art but, rather, multiple avenues. For every artistic phenomenon, there existed a composition of links, influences, and interactions that had to be collected, assembled and interpreted. For Marc, the main design challenge was "to identify learning activities and assemble didactic resources that would allow students to learn from multiple perspectives." 


Meta-reflection: Introduction of innovative design concepts
Although the majority of new online courses at KU required simple online transfers of
existing F2F courses, it is uncommon for an instructional designer like Marc, who
specializes in distance education, to make observations during F2F sessions in class. But
given the difficulty Robert had clarifying his learning approach and the uncertainty
involved in transposing it online, this unusual strategy seemed necessary and appropriate
to better understand what Robert was trying to achieve.

\section{When understanding occurs}

After these observations and an ensuing discussion, Marc finally understood what Robert wanted to do. As Robert said: "I want to help my students deconstruct their learning and perceptions and thus develop new understandings of folk art." On the course website, Robert presented his course this way: "This course invites you to participate in the reconstruction of the interpretations that have been given to these styles by those who identify themselves with them. I invite you to enter into the very heart of a post-hippie, artistic practice by means of a reconstruction where you will become the masters of this work."

Robert: By approaching the course contents in this way, we by-pass the problem of an in-depth analysis of the folk arts of the late $20^{\text {th }}$ century. To study all of the artistic movements in 15 weeks is impossible. I nevertheless intend to approach a few of the more important artistic movements, but also offer every student the opportunity to research, document, analyze, and 
comment on the work of a specific artis,t and to present his/her own personal understandings of the artist's work.

It was at this point that Marc finally understood Robert's instructional plan. But it was still necessary to set up the required learning activities and choose the technological tools best suited to manage all of this online. Time for reflection was needed.

\section{Meta-reflection: Marc's understanding of Robert's learning approach.}

Looking back, Marc realized that the learning approach Robert is trying to create is the fruit of his own personal evolution over the last few months. Given the many schools of thought in folk arts in the late $20^{\text {th }}$ century, Robert is challenged by the fact that it is impossible to review all of the possible content. Moreover, over the last decade, the Internet offers a vast quantity of rich and quality material that is largely sufficient for use in university teaching. According to Marc, there is such an abundance of content online today that Robert will quickly realize how easy it is to send students out to explore contents that deal with the specific artistic movements that they are interested in and thus, to build knowledge that is meaningful to them.

\section{A Web 2.0 challenge}

After a few weeks of contemplation and research, Marc got an idea and presented it to Robert:

I recently attended a conference where an arts teacher suggested to her grade school and high school students to go on the Web and find video clips, pictures, or audio clips, and to modify them to turn them into new 
and original work. She spoke about the "Culture of remix." To share their work, the teacher used a blog where all of her students posted their creations for the critique of their peers.

Marc went on to say:

By definition, a blog is a Web site, usually published by one individual, that deals with a specific subject and that is updated regularly. The articles or posts of a blog are presented in reverse chronological order and each of the posts can be commented on. These posts can contain texts, hyperlinks, pictures, sound recordings, and video clips that are all connected visually, which is not the case for discussion forums. I think that this tool would meet your need to offer a working space for your students to reflect, create, produce, and share, and to critique and comment on the work of their peers.

Robert: $\quad$ Now that is a very good idea. I'm ready to try it. I am going to take some time to define the learning activities around the blog.

Marc was delighted with this solution, but unfortunately KU didn't have the institutional tools to create and manage blogs. He had to find a solution to this problem. Marc explored the possibility of using a commercial tool like $\mathrm{Ning}^{1}, \mathrm{Blogger}^{2}$, and so on. These tools are interesting but they required a subscription without the assurance of sustainability over time. What would happen if one of these tools were to disappear during the course of a term? It would be rather disconcerting, actually, downright disasterous, but what was even more troubling was the fact that the students' work would be posted on external servers over which $\mathrm{KU}$ had no control. Furthermore, KU would have no control over how the companies hosting these blogs would use student data. Another possibility was to use an existing open source blog tool and adapt it to run on KU servers. The development of a specific blog tool at KU would mean that they wouldn't having to pay for a commercial product and it would also avoid the problem of

\footnotetext{
${ }^{1}$ http://ca.ning.com/

${ }^{2}$ http://www.blogger.com/
} 
having to post student work on external servers. Marc began to persuade the Office of Teaching and Learning to develop such a tool using the WordPress ${ }^{3}$ platform.

In March, Robert finalized the design of the C2-O learning activities. Just like C1-O, C2O presented a variety of contents within several modules. The main difference, compared to the first course, was that $\mathrm{C} 2-\mathrm{O}$ content was limited to some general schools of thought in folk art. Students learned through reading and viewing Internet-based video clips. The discussion forums were maintained. On the other hand, the question-and-answer activities were replaced by the production of ongoing postings to the blog.

Table 4 presents how the various activities on the blog would unfold. The students were required to choose a given school of thought in folk art that had emerged after the 1970s. They had to obtain approval of their subject of study upfront from Robert, during the first two modules of the course. Afterwards, from module 2 onwards, students were required to produce six posts at the rate of one post every two weeks. Each student had a personal blog on which to share his posts that were to contain the following elements (E):

1- A summary of the various schools of thought of folk arts from 1900 to 1969.

2- A summary of their object of study.

3- The social space surrounding their object of study.

4- The stylistics of their object of study.

5- The links between social space and the organization of the chosen folk arts school of thought.

6- A personal appreciation of the object of study.

\footnotetext{
${ }^{3}$ http://www.wordpress.com
} 


\begin{tabular}{|l|c|c|c|c|c|c|c|c|c|c|c|c|c|c|}
\hline \multicolumn{10}{|c|}{ Table 4- Organization of the activities on the blog of C2-O } \\
\hline Modules & 1 & 2 & 3 & 4 & 5 & 6 & 7 & 8 & 9 & 10 & 11 & 12 & 13 & 1 \\
& Choice of subject & CS & & & & & & & & & & & & \\
(CS) & & E & & E & & E & & E & & E & & E & & \\
\hline Parts (P) & & 1 & 2 & & 3 & & 4 & & 5 & & 6 & & \\
\hline Feedback (F) & & & F & & F & & F & & F & & F & & F6 & \\
& & & & 2 & & 3 & & 4 & & 5 & & & \\
\hline $\begin{array}{l}\text { Critical analysis } \\
\text { (CA) }\end{array}$ & & & & & & & & & & & & & C & \\
\hline
\end{tabular}

The students could choose the order in which their posts would appear. For supervisory purposes and to answer students' questions, Robert offered individual feedback on posts every three weeks. Students could rewrite their posts and comment on the posts of their peers at any time. Finally, students were required to consult their peers' blogs throughout the session and were required to produce a critical analysis (CA) for three of them. These critical analyses were to be sent to Robert before week 14 of the 15 -week term.

\footnotetext{
Meta-reflection: What Marc thinks of Robert's approach to learning?

Marc notices that university professors, including those at KU, use ICTs and digital resources taken from the Internet to emulate their "traditional" practice of teaching on campus. These tools and resources are essentially used to present content and, at most, to enrich the existing course content. According to Marc, the reasons for limited use of Web 2.0 tools by faculty were twofold: first, due to their philosophies of teaching, the majority of faculty were not very inclined to use tools that allowed students to produce and share content, although this was not the case in Robert's C2-O. The planned use of the blog
} 
exemplified a philosophy of teaching centered on student needs and on their progress through the acquisition of knowledge rather than on the one-way transmission of content from the professor to his students. In the C2-O course, students could choose a theme to explore, learn it well, and confront their ideas with those of their peers. Robert modified his role of professor by aiming to guide, criticize, and supervise his students rather than transmitting content.

The other explanation as to why there was such little use of Web 2.0 content in courses was the fact that, although the discussion forum tool was easily accessible in platforms such as BlackBoard, Moodle, and so on, university professors were not very familiar with other Web 2.0 tools such as blogs, wikis, or bookmark sharing. One can thus understand their lack of interest in using tools to which they did not have ready access.

\section{The end of the first terms}

At the end of the first two terms during which Robert's two courses were offered online, the level of satisfaction was high among his students and the same was true for both Robert and Marc. Student comments in the discussion forum in both courses were eloquent. Robert summarized them as follows: "The comments I've been getting from my students are well thought out and their vision of folk art has been completely transformed... The objectives had been reached in both courses. Of course, some problems were identified along the way but, on the whole, these were relatively simple to solve. Minor improvements would continue being made before the next term. 
During a post-course debriefing session, Robert commented on the strategy of using Internet-based digital resources.

Robert: $\quad$ The strategy of using video podcasts was successful in both courses. I had to replace only two or three hyperlinks during the term. The replaced links were simply hyperlink, or IP address changes, pointing to the same contents. The implementation of this strategy was thus effective.

Concerning the work accomplished with the blog tool:

Robert: $\quad$ During the winter term in the C2-O course, the use of the blogging tool was a great success. The main problem was that the work on the blog was perceived by students as "normal" term research work, necessary to produce a paper to be handed in at a later date. The old habit of "doing things at the last minute" got the upper hand as opposed to the desired approach.

Marc: Do you think closer supervision of this activity might be needed?

Robert: Yes, I do. I was thinking that from now on, there should be some kind of order for each object and for the parts of the work to be dealt with. Furthermore, to facilitate the supervision and consultation of blogs, the main improvement could be to use one blog for all of my students instead of a blog per student. Reviwings posts would thus be simpler for me and for my students as well.

\section{A relationship of trust emerged}

To date, both of Robert's courses have been offered online three times. The courses were transferred from an existing LMS to a new institutional system developed at and by KU. During this migration process, Marc coordinated the course transfer, knowing that he could improve a few files, as well as some of Robert's instructions for these courses, without having to consult him beforehand. Meanwhile, Robert began developing two new online courses. Marc was not very involved in this latter development but that didn't 
worry him. Although Marc went for long periods of time without any news from Robert, he knew that Robert was very capable and that he would call him for instructional or technological advice if it were needed. A feeling of mutual trust seemed to have been well established.

However, this was not the case at the beginning of the project. At that time, Robert was quite preoccupied with teaching his face-to-face courses. The online versions were of secondary concern to him, although Marc had great expectations on this matter. While they respected each other, they gradually found a way to merge both of their concerns. On the one hand, Robert opened himself up to online learning and to instructional possibilities that allowed him to go well beyond the limits of his face-to-face courses. He also applied his instructional intentions in a more concrete way. Marc, on the other hand, due to the nature of Robert's courses, also had to go beyond his own limits and to become familiar with a new learning approach in order to find original solutions to meet the needs of the professor. This resulted in a relationship of trust being established which was based on collaboration wherein the expertise of both was recognized and appreciated by the other despite the different ways in which they evolved during the project. They agreed that, if necessary, they could call on one another for help at any time.

\section{Instructional design problems and solutions}

From an instructional design point of view, this case raises four problems or interesting elements of design.

The first element is the influence of face-to-face teaching habits that determines the choice of learning and assessment activities for online courses. In the beginning, Robert 
planned the development of his face-to-face courses according to the traditional way in which university courses are taught. He didn't think a lot about whether or not this approach would be applicable to online courses. It was only after a time, when he became aware of various elements of online posting, that questions began to emerge in his mind. For an instructional designer like Marc, this adhesion to the traditional practice of F2F teaching was often a source of frustration. It limited possibilities for improvement and innovation. To overcome this difficulty, the strategy of in situ observation proved useful in that it showed Robert that Marc was truly concerned and that he really wanted to better understand Robert's teaching practice and how he might help him. In short, Marc was trying to better understand Robert's instructional intentions, compare his teaching practice to institutional state-of-the-art strategies for DE, and see how Robert's courses could be converted to online courses. This same strategy could be used again and again.

The second element worthy of mention is the restrictions that Canadian copyright legislation places on the use of Internet-based materials. This legislation is very restrictive on the use of copyrighted material for educational purposes. Although the Internet is filled with interesting resources for education (pictures, graphics, photographs and videos), sadly, the prohibitive cost associated with obtaining the rights to use such material does not encourage usage. In spite of the abundance of available resources on the Internet, their ongoing availability remains an issue. In Robert's courses, the use of online resources quickly became essential to demonstrate various notions and concepts in the field of folk arts. The strategy of using hyperlinks leading to multiple resources (videos) to demonstrate concepts, combined with student support in searching for and sharing new resources turned out to be an innovative and effective solution to the 
copyright problem. In the end, the use of hyperlinks and the requirement that students find new links to existing resources allowed Robert to put together a collection of hyperlinks that constituted his core material. This strategy amply compensated for the possible disappearance of some resources and it even ultimately improved Robert's choice of digital resources.

The third element is the implementation of a blog tool. The use of this kind of tool is currently very limited at KU. Marc took a fair amount of time before coming to the conclusion that this tool was indeed the answer to Robert's instructional needs. Robert had been trying to find a way to bring his teaching practice out of the well-established university practice of asking students to produce an often linear and chronological term paper. Structured within a conceptual framework, the blog tool allowed students to develop richer editorial work comprised of several parts all connected to the same learning objective, thereby allowing them to understand the links between the various elements.

This case also brought to light an important aspect of an instructional designer's work. This aspect is not as closely connected to the problems of design as the ones presented previously. It is set at a more intermediate level and deals with communication and the need for developing a trusting relationship between a professor and the instructional designer assigned to a given course project. Given the change in orientation of the learning approach for $\mathrm{C} 2-\mathrm{O}$, we find an example of a case that demonstrates the extent to which communication between an ID and a professor can, at times, be difficult, not because of anyone's negative attitudes but simply because they don't speak the same working language. On the one hand, Robert can't translate his ideas into the language of 
instructional design and, on the other hand, Marc can't decode Robert's instructional intentions to be able to advise him adequately. In many cases, this kind of miscommunication can constitute an obstacle that can build to a breaking point in the development of a project.

Through a series of small actions initiated by Marc - for example, temporarily putting the unsettled questions regarding the online development of Robert's courses on hold; taking the time to observe Robert in his face-to-face sessions; striving to better understand Robert's specific learning objectives and encouraging him to clarify them-Marc managed to win Robert's trust. In this way, a real setting for collaboration was created, one that allowed them both to find satisfactory solutions in spite of the different cognitive processing patterns of each individual.

\section{Conclusion}

In the end, both newly-developed courses presented a number of design issues that are fairly common in DE. Robert, the professor, is proud and satisfied with the solutions they found and so is Marc. Due to the design problems outlined in this case, there is no doubt that an instructional designer's job revolves around challenges of various types. Beyond the educational challenges influenced by traditional teaching methods used in university settings, it is also important to highlight the challenges related to technological, communication, and interpersonal relations that must be faced. 


\section{References}

Audet, L. (2010) WIKIS, BLOGUES ET WEB 2.0. Opportunités et impacts pour la formation à distance. Réseau d'enseignement francophone à distance du Canada (REFAD). [Consulted on December 12 ${ }^{\text {th }}$ 2012].

http://www.refad.ca/nouveau/Wikis_blogues_et_Web_2_0.pdf

Gagne, R. M., \& Briggs, L. J. (1979). Principles of instructional design (2 ${ }^{\text {nd }}$ Ed.). New York: Holt, Rinehart and Winston. 